\title{
Patrimonio cultural y paisaje en la siembra del arroz en Rocha, Uruguay. Lascano, capital del Arroz.
}

\author{
Cultural Heritage and Landscape in the seed of rice in \\ Rocha, Uruguay.
}

Antonio Moleón ${ }^{1}$, Joana Batel ${ }^{2}$ y Diego Palau

\begin{abstract}
En el marco del proyecto "Pueblos Invisibles" desarrollamos un primer acercamiento a la territorialidad que representan los enclaves interiores del Departamento de Rocha, sus características; interacciones; fortalezas; debilidades; oportunidades y amenazas. Desde la ciencia "dura" obteniendo datos de diversas fuentes como el INE, PROBIDES, IDR entre otras siendo estos corroborados y rectificados mediante visita de campo, donde se lograron varios diálogos y entrevistas con actores locales de los más diferentes ámbitos, nos permitió establecer un primera aproximación propositiva que refiere al desarrollo local a través de la educación como "motor" de crecimiento aprovechando la sinergia que genera el triángulo identidad-historia-oficio siendo el producto de este en su expresión mínima el grano de arroz tal cual es para el cuerpo humano una célula.
\end{abstract}

En este articulo detallaremos el resultado del estudio sobre la ciudad de Lascano definida en Capital, Arroz, Paisaje, Patrimonio, Desarrollo.

Palabras clave: Territorialidad; Desarrollo; Identidad

Within the framework of the "Invisible People" project we developed a first approach to the territoriality represented by the interior enclaves of the Department of Rocha, its characteristics; interactions; strengths; weaknesses; opportunities and threats. From the "hard" science obtaining data from various sources such as INE, PROBIDES, IDR among others being corroborated and rectified through a field visit, where several dialogues and interviews with local actors from different areas were achieved, allowed us to establish a first propositive approach that refers to local development through education as a "motor" of growth taking advantage of the synergy generated by the

\footnotetext{
${ }^{3}$ privadavia@gmail.com
}

2 
Antonio Moleón, Joana Batel y Diego Palau (155-170)

triangle identity-history-trade being the product of this in its minimal expression the grain of rice as it is for the body human cell.

In this article we will detail the result of the study about the city of Lascano defined in Capital, Rice, Landscape, Heritage, Development.

Keywords: Territoriality; Development; Identity. 
DIMENSIÓN POLÍTICO - JURÍDICO - INSTITUCIONAL

Historia - división administrativa - relaciones locales y regionales

La ciudad de Lascano está situada al noroeste del departamento de Rocha sobre las rutas 14 y 15, sede del municipio, rodeada por importantes bañados y humedales del Este del país. Fue fundada en los campos del estanciero Francisco Fernández, el 10 de febrero de 1876. Originalmente se la denominó "Tres Islas" no existiendo antecedentes oficiales del porqué de la denominación (se asume que fue debido a las formaciones de islotes sobre la zona de humedales ya que la ciudad está implantada en un sector con características del suelo que llevan ese nombre).

Como consecuencia de los diferentes trámites realizados ante el gobierno nacional para contar con autoridades policiales y los diversos servicios públicos, tomó el nombre del compadre de Francisco Fernández, el vasco Francisco Lascano que fue quien firmaba los documentos, al ser Francisco Fernández analfabeto. Podemos ver en el plano de 1875 que Francisco Lascano poseía la fracción de territorio más pequeño, igualmente por lo expresado fue el Sr. Lascano quien dio nombre al Pueblo. Fue elevado a villa el 4 de julio de 1908 (Ley $N^{\circ} 3.304$ ) y a ciudad el 3 de noviembre de 1953 (Ley $N^{\circ} 11.784$ ).

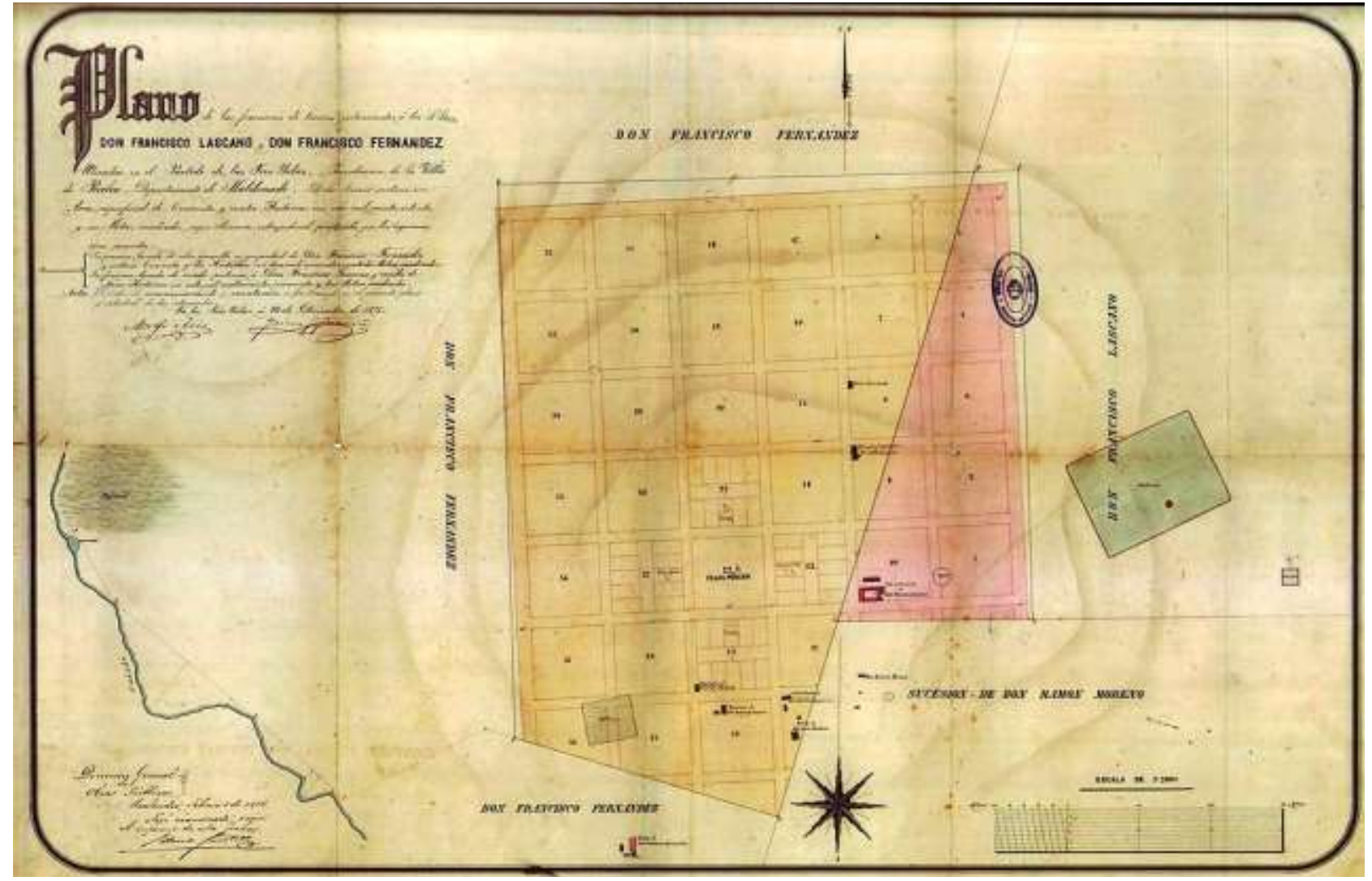

Figura 1. Plano de Fundación. Archivo IDR

La ciudad se emplaza en una planicie alta ubicada entre el Río Cebollatí y el bañado de India Muerta al norte del departamento, en la intersección de las rutas 15 y 14 y próximo a la intersección de las rutas 15 y 19. Esta ubicación le permite una fácil conexión con todos los centros urbanos del departamento y con amplias zonas del territorio, así como con la ciudad de José Pedro Varela en el departamento de Lavalleja y con la ruta 8 y la ciudad de Treinta y Tres. 
Se trata de una ciudad con un importante núcleo central, conformado por un rectángulo de 1.200 metros por 1.200 metros aproximadamente y una cuadrícula de manzanas cuadradas, con un alto índice de ocupación de predios (próximo al 90\%) y extensiones posteriores que, en general, continuaron con la lógica de la manzana y la calle buscando continuidades en el viario. El área efectivamente urbanizada es de 290 hectáreas lo que constituye el $95 \%$ del área autorizada para fraccionar.

La ciudad tiene un alto índice de viviendas desocupadas (20\% según datos del censo 2011) y una densidad de población neta baja: 26 habitantes por hectárea, con una población de 7.645 habitantes (Censo INE, 2011). Es una ciudad compacta en gran parte de su extensión, comienza a perder esta característica en las ampliaciones más recientes, dejando áreas de uso agrícola inmersas en la zona urbana. Este fenómeno se ve potenciado por la construcción por parte de MEVIR de un importante conjunto de viviendas sobre la ruta 15 al norte, fuera del área urbana. Lascano se ha estructurado en forma concéntrica, teniendo a la plaza principal como origen formal. La principal zona comercial y de servicios de la ciudad coincide con este centro, quedando a cortas distancias aún de los sectores más alejados constituidos por las ampliaciones. Se encuentra en un segundo tramo, en cuanto a cantidad de servicios tenidos en cuenta para la caracterización urbana, constituyendo una centralidad regional de segundo nivel, atendiendo con sus servicios a los centros poblados de Cebolla y Velázquez y una amplia zona rural de producción agrícola. Es de hacer notar que la enseñanza secundaria no ofrece todas las opciones de bachillerato.

En el área central las construcciones son contiguas, sin retiros frontales ni laterales, las calles están pavimentadas con asfalto y las aceras con baldosas, sin árboles o plantas de ornato público. Las construcciones son de buen nivel y se encuentran en buen estado de conservación, constituyendo fundamentalmente, en una vivienda unifamiliar por predio en una o dos niveles. Se trata de una ciudad con un alto grado de homogeneidad formal, con espacios públicos de agradables proporciones. En las zonas de ampliación se han incorporado retiros a las reglamentaciones y el índice de ocupación de predios baja notoriamente. Las calles están pavimentadas con balastro y no existen aceras, constituyendo un tejido abierto, con presencia de verde en retiros frontales y calles. Lascano en el vértice norte en la intersección de las rutas

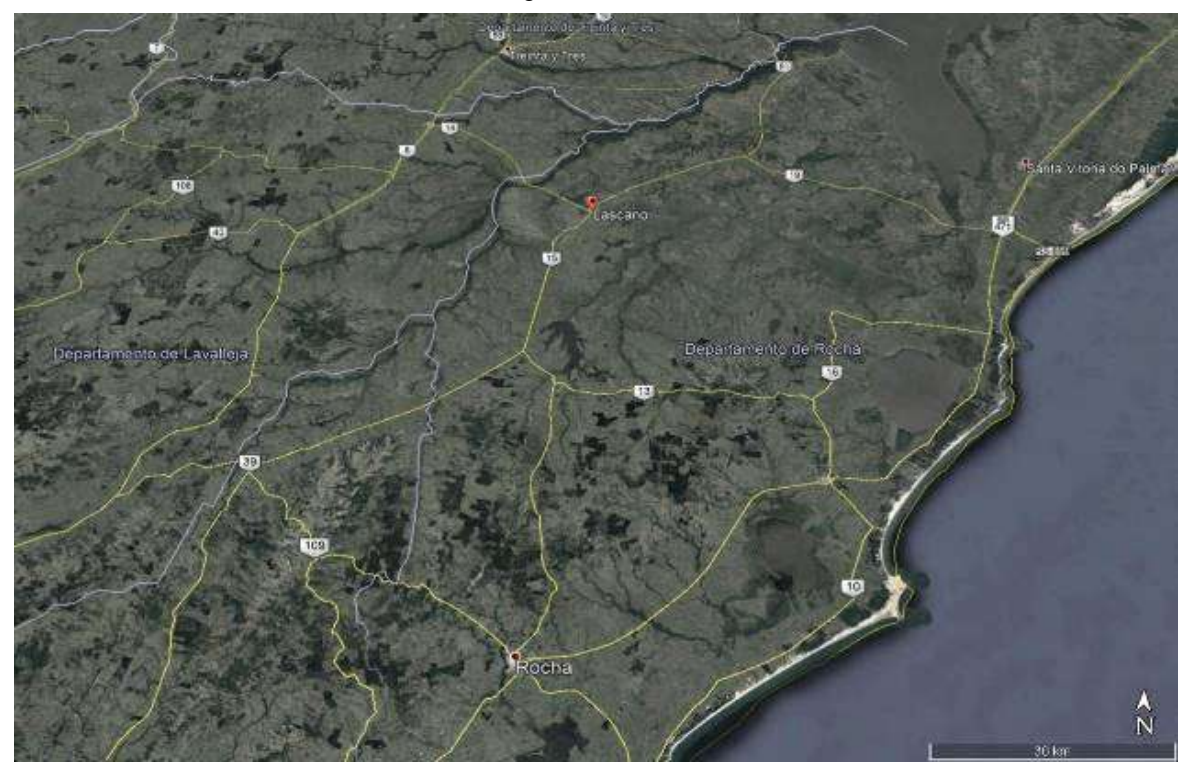

15 y 14 junto con el triángulo conformado por Rocha, Castillos y Chuy sobre la ruta 9 en la base, constituyen la base urbana de la estructura territorial del departamento, donde vive el $74 \%$ de la población y están radicados los principales servicios a la población y a la producción, comercios y actividades productivas urbanas.

Figura 2. Plano de la

Región. Fuente: Google Earth, 2017. 
Lascano constituye un segundo nivel de centralidad, de carácter intermedio con servicios para sus respectivas poblaciones, los centros poblados de menor dimensión y áreas rurales próximas. Se toman en cuenta todos los factores considerados y particularmente los servicios de educación y de salud. Este nivel es designado como centro de servicios regionales, donde Castillos y Chuy cuentan con redes de saneamiento y en Lascano se han comenzado las obras de saneamiento.

Las Directrices Departamentales proponen como línea estratégica dotar a los centros urbanos de "alta calidad ambiental, poniendo en valor y complementando las cualidades hoy reconocibles, realizando proyectos y promoviendo actuaciones que mejoren las condiciones de los lugares más desprovistos".

En materia de desarrollo del sistema urbano y del sistema de centralidades, las acciones apuntan a mejorar la calidad ambiental de los centros urbanos no promoviéndose extensiones significativas en ninguno de ellos y a la vez ordenándose su crecimiento en caso de éste verificarse.

La Centralidad Lascano (Rocha), José Pedro Varela (Lavalleja) y la capital del departamento de Treinta y Tres, tiene como principal denominador común de esta área, el cultivo e industrialización del arroz, habiendo logrado extraordinarios resultados en tecnología aplicada a la mejora de la productividad. En efecto, la sinergia se verifica en la proximidad y complementariedad de actividades con la presencia de las empresas SAMAN y COOPAR a Ias que se agregan, la gremial de los cultivadores de arroz (ACA) y el Instituto de Investigaciones Agropecuarias (INIA) completando el círculo virtuoso del I+D. Esta convergencia de instituciones también deviene en beneficios económicos que se manifiestan en la fuerte dinámica económico-financiera asociada a la cadena productiva. Este entramado institucional se complementa con una sociedad que vive la "cultura" del arroz. En efecto, como en toda cadena productiva la componente social es la piedra angular de su éxito o fracaso y la zona arrocera del Este uruguayo no es la excepción. Si bien las localidades citadas son el centro de gravedad de la cuenca arrocera nacional, debe establecerse que ésta se extiende incluyendo espacios productivos y urbanos del departamento de Cerro Largo, Treinta y Tres y otras localidades del propio departamento de Rocha, como Cebolla, San Luis al medio y Chuy. Asimismo, las tierras bajas del vecino Río Grande do Sul opera con lógicas similares; lógicas que devienen en fuertes e históricos vínculos transnacionales.

Estratégicamente las directrices departamentales proponen avanzar hacia un Departamento integrado a la región Este del país y a los vínculos transfronterizos aprovechando los valores comunes y las complementariedades mediante el ejercicio de modalidades de gestión compartida y articulación de iniciativas y servicios, por instituciones de gestión integrada de los ambientes (sierras y cursos de agua) compartidos y por ámbitos de gestión integral y complementaria de las áreas urbanas y naturales transfronterizas. 


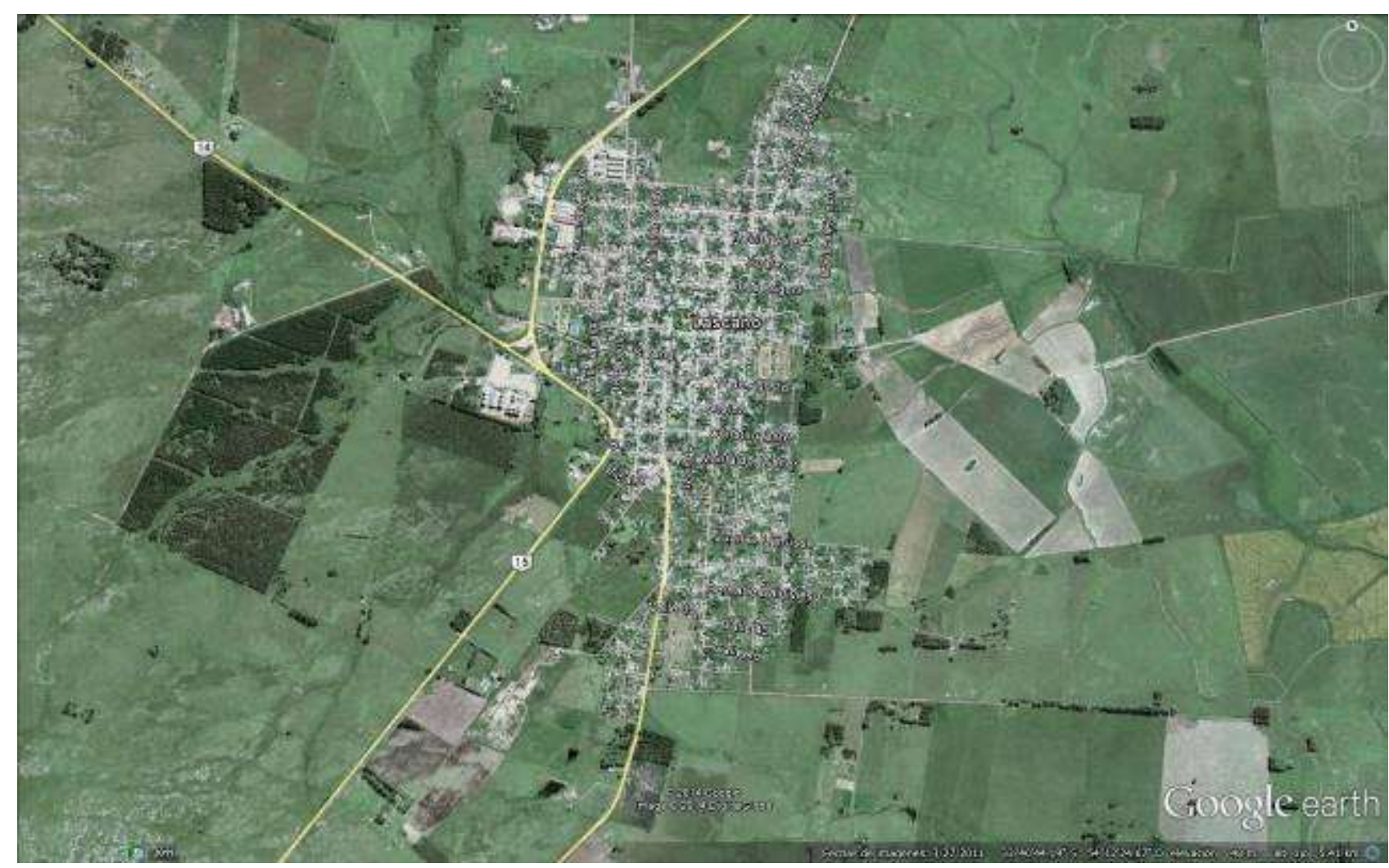

Figura 3. Plano de Lascano. Fuente: Google Earth, 2017

\section{DIMENSIÓN FÍSICO - ESPACIAL}

Infraestructura - servicios - espacio público

El sistema viario es similar en toda la ciudad, una red de calles en cuadrícula permite el tráfico rodado y movimiento peatonal. Se puede considerar que hay una red suficiente para el tránsito local de vehículos de Lascano. No precisa de semáforos en toda su red de calles, ni de transporte público. Las distancias son fácilmente abarcables caminando. La dimensión de los viales y veredas en relación con el número de viviendas es suficiente. Posee calzada para tránsito de dos vehículos en ambos sentidos, espacio en ambos lados para poder estacionar y veredas con espacio suficiente para pasar dos personas a la vez.

La circulación de vehículos motorizados dentro de la ciudad de Lascano está en cierto modo restringida. Los vehículos de gran tonelaje tienen dificultades para acceder a todas las calles del centro. Cualquiera de los demás, motos y autos tienen total flexibilidad dentro de la red viaria. La circulación de peatones es completamente libre. La organización de la circulación en relación con la edificación permite que todas las viviendas tengan acceso directo a la calle. En toda la ciudad de Lascano el aparcamiento se hace en la vía pública. Todas las calles pavimentadas tienen zona señalizada en ambos lados destinada al aparcamiento de vehículos motorizados. Además, muchas de las viviendas tienen garaje propio con su correspondiente entrada a nivel de la calle. Parkings públicos como tal no hay, al día de hoy no se estima necesario. El índice de motorización se cree que es un auto por vivienda de media, además de algún vehículo motorizado de dos ruedas, que para las distancias cortas dentro de la ciudad son muy utilizados. Además, también se calcula una gran flota de vehículos agrarios para el cultivo de los campos cercanos.

Hemos hecho una estimación del número de plazas que podría llegar a albergar la ciudad de Lascano en la calle: Suponiendo que para aparcar un auto se necesita como mínimo 5 metros y 
las manzanas llegan a tener 100 metros por cada lado, restando puertas de garaje de cada casa suponemos que tenemos 70

metros útiles. 0 sea $70 \times 4=280$ metros disponibles, $280 / 5=56$ vehículos por manzana. 115 manzanas $\times 56$ vehículos $=6.440$ vehículos en total en Lascano.

El transporte público dentro de la ciudad de Lascano no es necesario, sus distancias son cortas y con el transporte privado es suficiente. El transporte público que ofrece la ciudad de Lascano, son 5 autobuses repartidos a lo largo del día, que van directo a las ciudades cercanas de Cebolla, Velázquez y Rocha. Las rutas 14 y 15 comunican Lascano con el resto del departamento. La conexión con otras ciudades con transporte público sería necesario efectuarla mediante transbordo. La distancia a la ciudad de Montevideo es de 248,3 kilómetros y se estima un tiempo de 3 horas y 46 minutos.

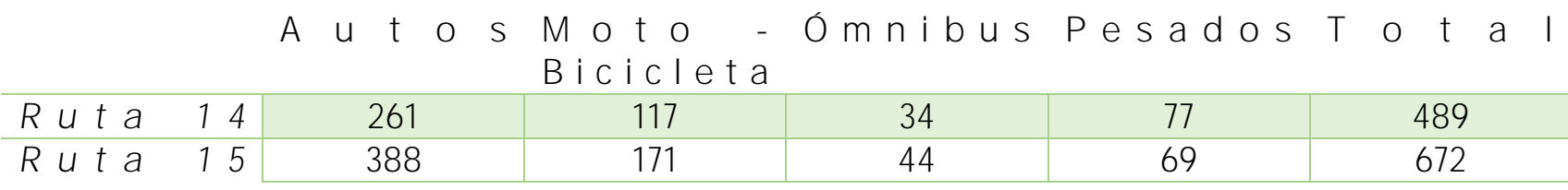

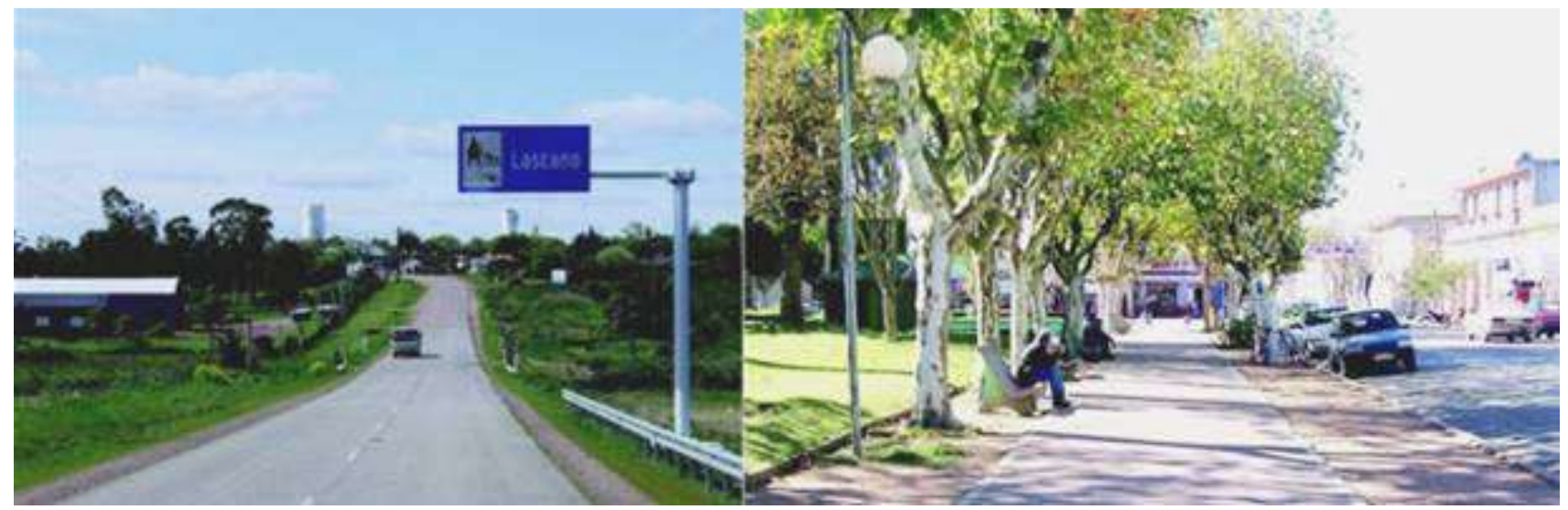

Figuras 4. y 5. Acceso Sur y Plaza Principal. Joana Batel, 2014.

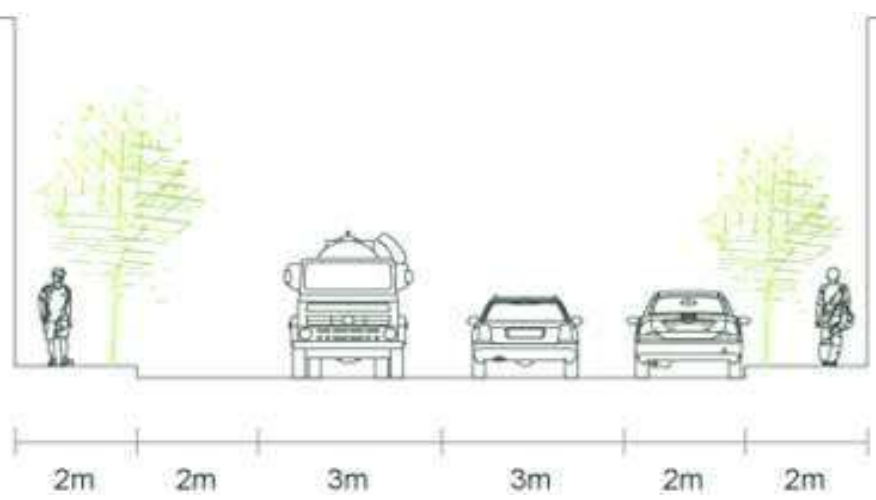

Figura 6. Perfil Urbano. Antonio Moleón, 2014.

La estructura de la edificación presenta las características de densificación baja (no hay edificación en altura de más de 3 niveles, cuya superficie parcelaria ronda entre los 500 y 800 metros cuadrados cada una.

Su ocupación en un gran porcentaje es de vivienda unifamiliar con casos de vivienda colectiva desarrollada en horizontal.

Los grandes edificios son organismos de gobierno. El uso de la planta baja o acceso desde la acera es mayoritariamente de uso de pequeños comercios. 

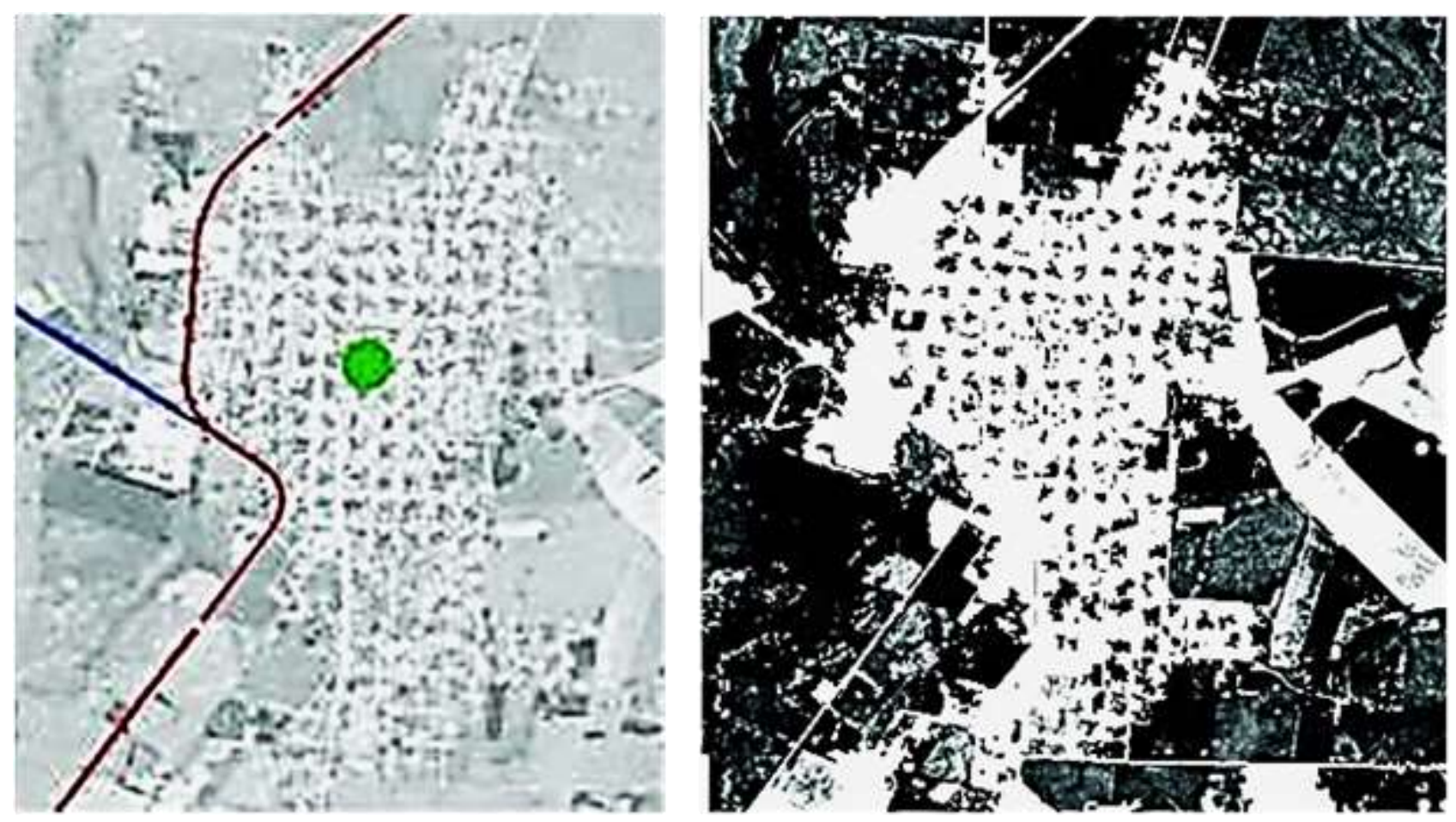

Figuras 7 y 8 . Rutas de accesos. Urbano-rural. Antonio Moleón, 2014.
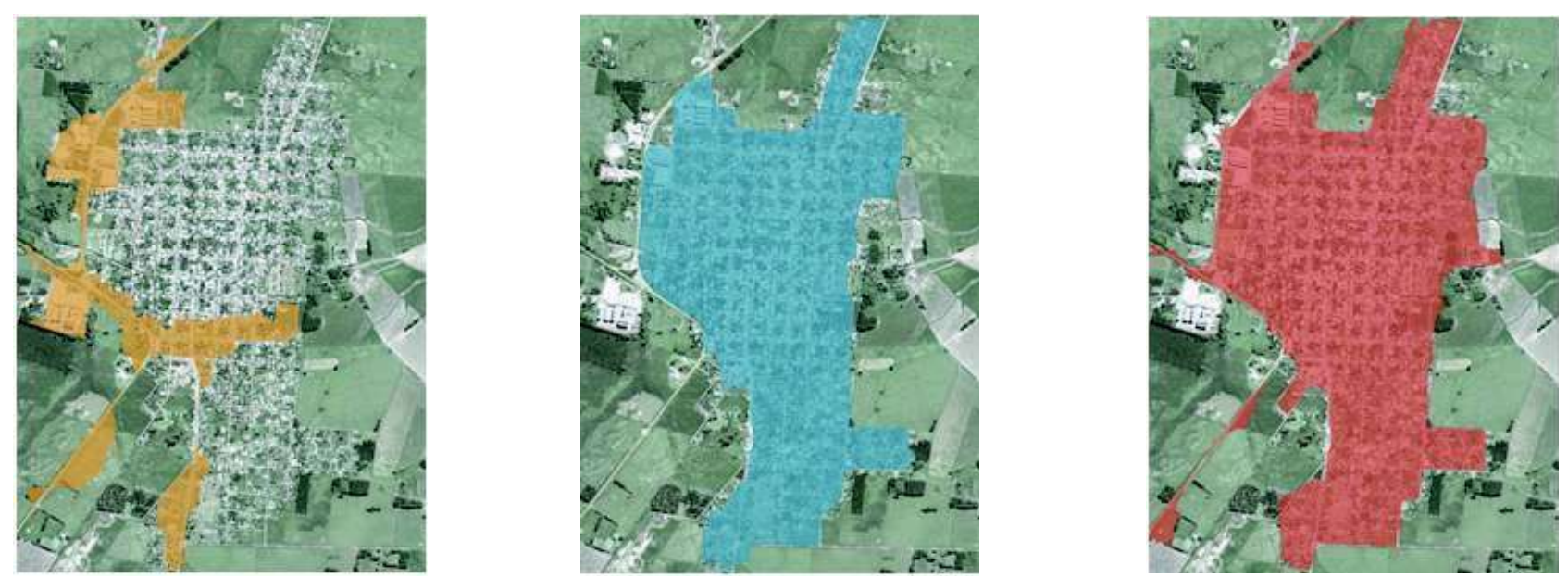

Figura 9. Vías de Circulación (Naranja $=$ Transporte Pesado; Celeste $=$ Automóviles; Rojo $=$ Peatones). Antonio Moleón, 2014.

Hasta hace unos años, la recolección de desechos se hacía puerta por puerta, pero en una nueva propuesta de la intendencia, los desechos se tienen que depositar en contenedores. Estos contenedores están colocados estratégicamente en todas las calles para que los ciudadanos no tengan que caminar mucho. Con esta nueva propuesta ha mejorado mucho la limpieza de la ciudad. El mismo alcalde nos dijo que los primeros meses fueron complicados porque la gente no se adaptaba bien.

Los comercios están distribuidos por toda la ciudad de Lascano, pero sobre todo en el centro de la ciudad, son comercios particulares pequeños, en su mayoría de venta de productos de industria nacional.

El comercio principalmente abastece la propia ciudad de Lascano, no hay mucho intercambio de mercancías. La única excepción es la de industria arrocera que exporta a nivel mundial. 


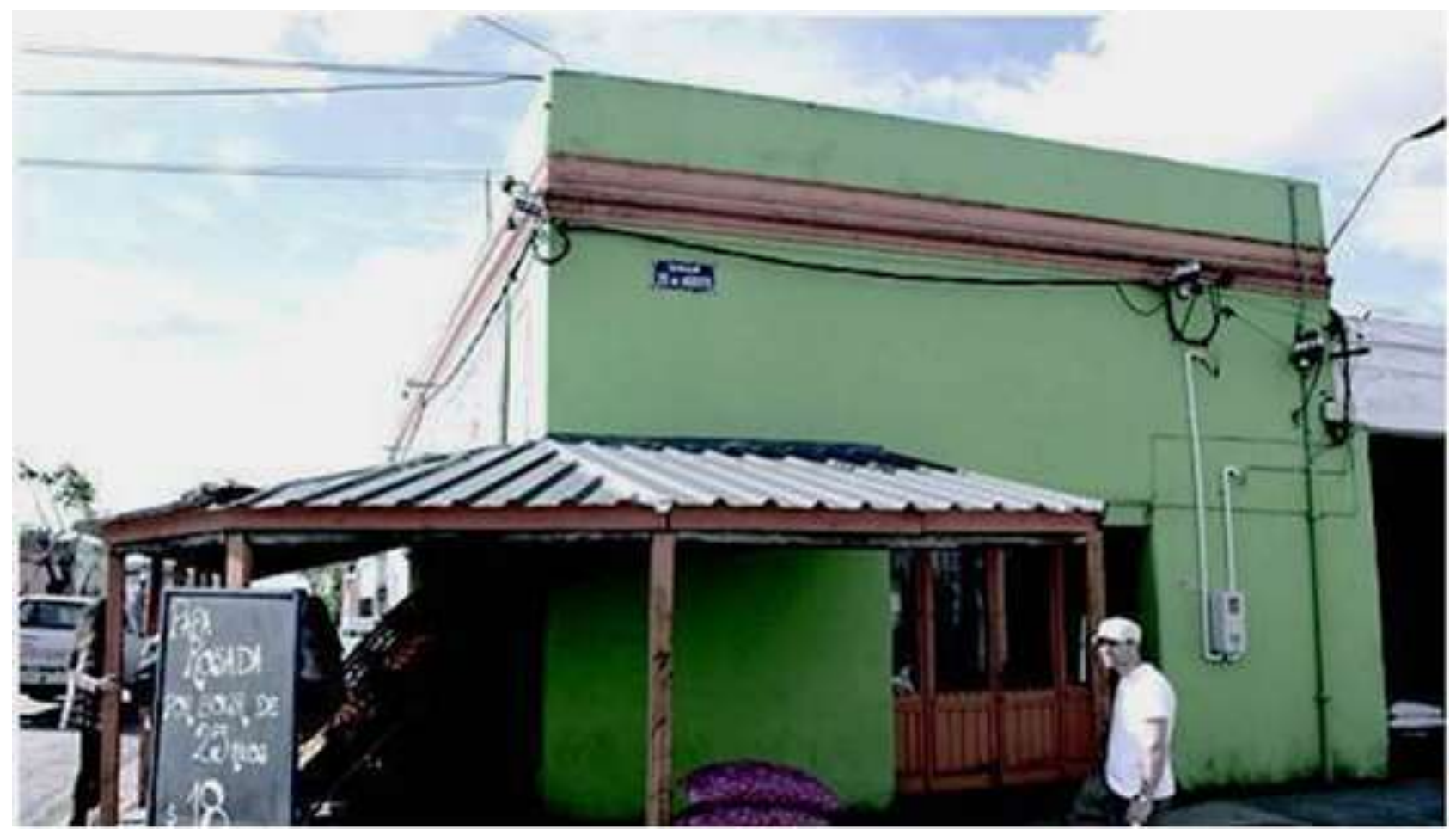

Figura 10. Vieja Pulpería. Joana Batel, 2014.

Lascano recibe una línea de $60 \mathrm{kv}$ desde Treinta y Tres por José Pedro Varela que abastece a toda la ciudad.

En cuanto a las obras de saneamiento existe un Plan Director desarrollado por OSE, actualmente el control de las pluviales se da por pendiente natural del relieve de la ciudad hacia los cursos de aguas cercanos ayudado por la poca parquización de los predios.

La Intendencia Departamental realiza la recolección de los residuos sólidos los que se vierten en los sitios de disposición final a cielo abierto (uno de ellos en las afueras de la ciudad).

En cuanto a las telecomunicaciones hay instaladas radio bases, cuyo centro de referencia es el Centro auxiliar de Lascano, cubriendo además Cebollatí y áreas vecinas. Cuenta con servicios de Televisión por cable, emisoras de radio AM y FM y prensa local. Cuenta con centro de salud (MSP) con internación y salas de parto, pero sin block quirúrgico. A nivel de centros educativos funcionan un centro CAIF, una escuela primaria privada, un jardín de infantes, un liceo público, una UTU y un centro MEC de referencia regional. En materia de vivienda Lascano cuenta con 3541 de acuerdo a los datos disponibles del Censo 2011, dos en modalidad colectiva de MEVIR.

A nivel de seguridad se asienta allí una seccional policial propia, cuartelillo de bomberos, defensoría pública, así como red de cajeros automáticos, sucursal bancaria de banca estatal, oficinas de correo y pago fácil y estaciones de servicios. En cuanto al hospedaje el mismo presenta debilidades tomando en cuenta posibles desarrollos culturales, cuando se promueven dos fiestas locales como la "Fiesta del Asado con cuero" y "La Fiesta de la Represa de India Muerta". 


\section{DIMENSIÓN SOCIO - ECONÓMICA}

Industria - migración - el arroz

Entendemos por recursos naturales todos aquellos elementos de este carácter susceptibles de ser aplicados a la generación de valores económicos. Existen múltiples clasificaciones de los recursos naturales que no parece del caso desarrollar en esta síntesis; por tanto, nos limitaremos a usar una clasificación provisoria de carácter geográfico que nos permita además lograr una regionalización del área local, aunque sea en forma preliminar, para luego tener una idea de la capacidad productiva de la localidad desde el punto de vista geográfico. A lo largo y a lo ancho de su superficie se suceden paisajes de llanuras, lagunas, embalses.

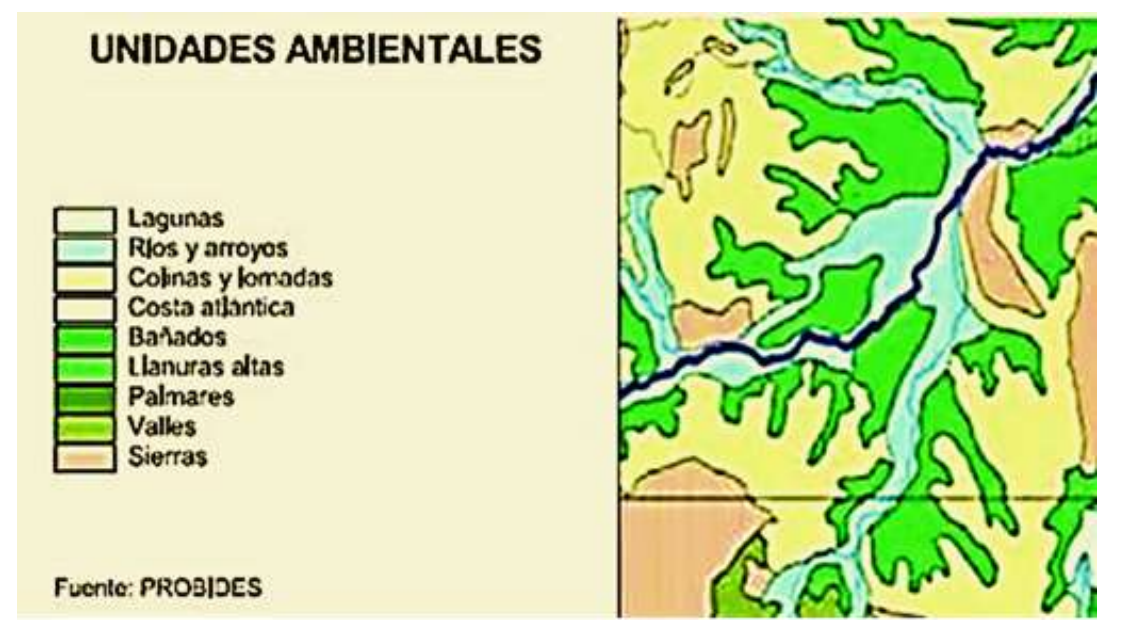

Figura 11. Unidades Ambientales. Fuente: PROBIDES, 2007.

El relieve es de colinas, con interfluvios convexos y pendientes entre 6 y 12\%. Los suelos son Brunosoles Lúvicos (Praderas Pardas máximas), francos y Argisoles Subéutricos Melánicos Abrúpticos, francos a veces moderadamente profundos (Praderas Planosólicas). Este padrón de suelos se da en el sur del Departamento de Treinta y Tres y norte de Rocha. Ambos se relacionan a áreas más disectadas o estalles, o a proximidad de afloramientos rocosos. El material madre está constituido por un débil manto (a veces discontinuo) de sedimentos limo arcillosos cuaternario sobre la roca del basamento cristalino. La vegetación es de pradera predominantemente estival y el uso actual pastoril. Ocupa áreas importantes al oeste y suroeste de Treinta y Tres, alrededores de Velázquez y sur del Departamento de Maldonado.

Los suelos profundos, bajos e inundables, natural o artificialmente aptos para el cultivo del arroz a partir de la década del 50 fueron testigos del comienzo de una etapa en la evolución de la producción agro pecuaria de Rocha, con el nacimiento de las cooperativas de productores tendientes a proteger a los mismos en la compra de sus insumos y en la venta de sus productos, así como a promover nuevas técnicas en la explotación de los campos.

En el año 1952 fueron fundadas con un mes de diferencia las cooperativas de Rocha y de Castillos y poco después, la Cooperativa Agropecuaria de Lascano. En esta misma ciudad, en el año 1961 fue creada la Cooperación Agraria Limitada del Arroz (Coopar) con el fin de centralizar el trabajo de industrialización, almacenaje y comercialización. 


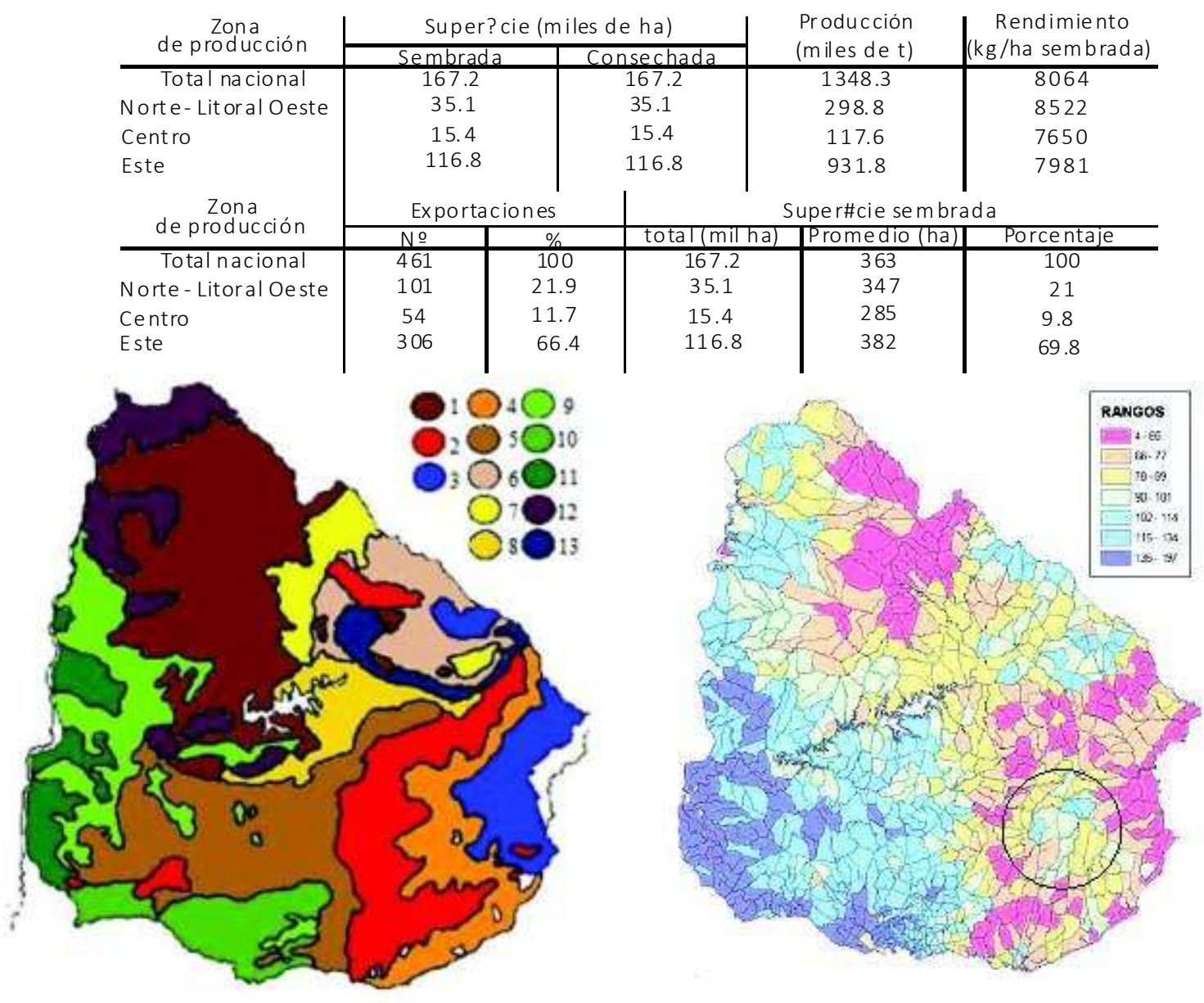

Figura 12. Siembra del Arroz. Encuesta de Zafra 2013-2014, DIEA-MGAP.

El cultivo del arroz, iniciado a comienzos de los años 30, ha mostrado un marcado dinamismo, particularmente a partir de la década del 60. En la zafra 2009-10 fueron sembradas 34.394 hás. en el Departamento ( $21,5 \%$ del total nacional). El sector arrocero tiene una importante escala, tecnología de punta, alto porcentaje de exportación, alto grado de organización en la cadena de producción, organización en la definición de precios, financiamiento, etc.

Las empresas arroceras están localizadas en Lascano y Chuy. Asociada a la producción arrocera existe una industria de procesamiento de productos derivados del arroz con dos empresas localizadas en la ciudad de Rocha (Coopar y Saman), siendo el $95 \%$ de la producción para destino de exportación y un $5 \%$ para consumo local. Como dato comparativo en la región, un uruguayo promedio consume $11 \mathrm{~kg}$. del grano al año, en Argentina y Brasil el consumo es de 40 y 70 kg. por persona por año y viendo al mundo, el mayor comprador de arroz, China, el consumo per cápita anual es de $200 \mathrm{~kg}$.

La relación de la ciudad de Lascano presenta similares características de movimiento poblacional y comunicación tanto con la capital departamental y poblados cercanos como con los departamentos cercanos, en particular con la localidad de José Pedro Varela (Departamento de Lavalleja), con el cual forma un centro territorial con amplias fortalezas para el desarrollo industrial. Los datos censales de 50 años muestran un crecimiento de la población en 30 años en casi un $66 \%$, asociado a la explosión de la industria arrocera, cayendo mínimamente un $5 \%$ en los últimos 20 años, particularmente en el periodo de recesión de la economía. Alrededor de un $95 \%$ de la población se sustenta por actividades directas o indirectas asociadas a los 
procesos del arroz. El 53 \% de la producción total se extrae de la región colindante, aunque esto en los años ha aumentado considerablemente.

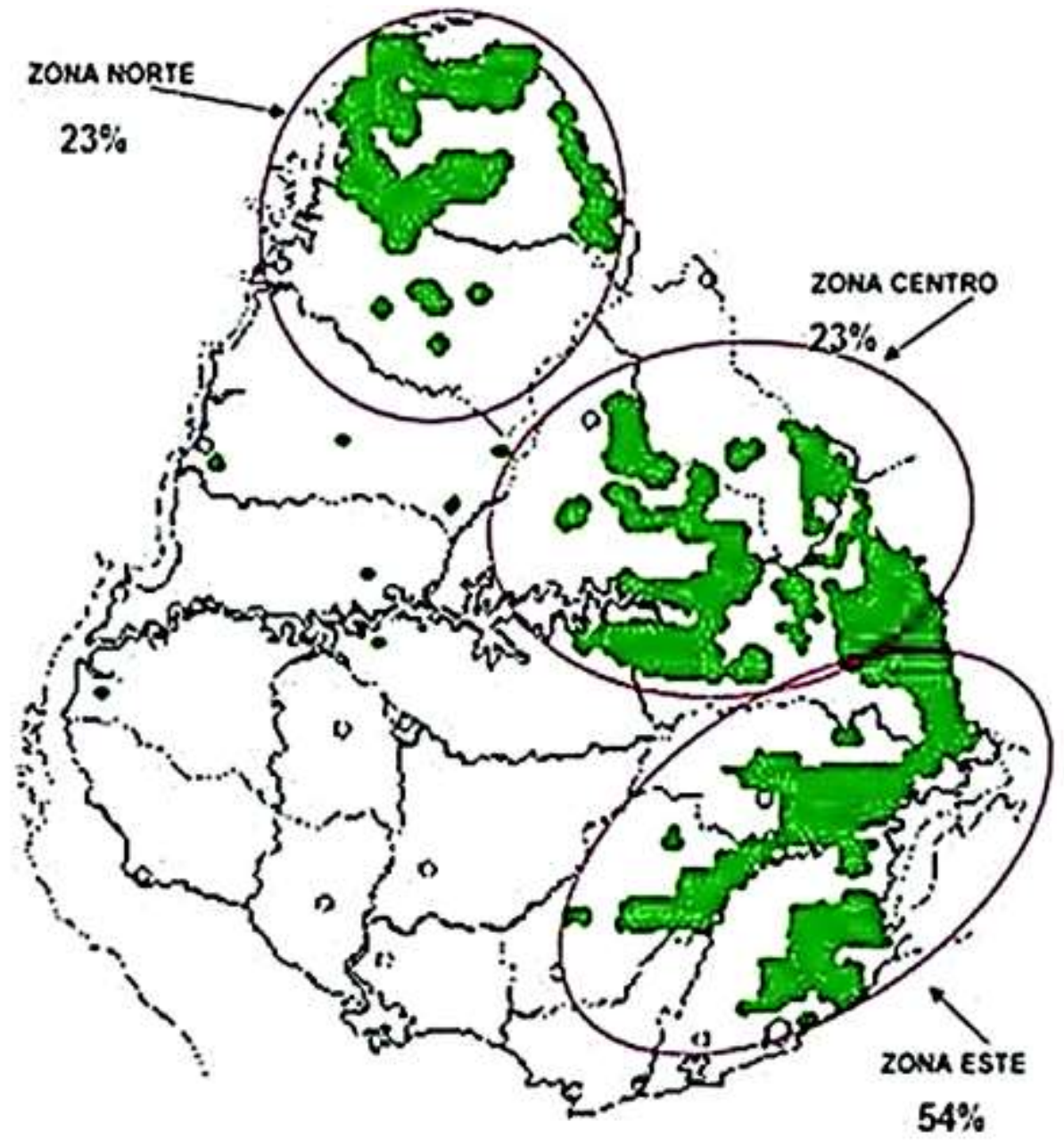

Figura 13. Siembra del Arroz. Encuesta de Zafra 2013-2014, DIEA-MGAP.

\section{DIMENSIÓN ECO - SISTÉMICA}

\section{Microclimas-relaciones-impactos}

Los humedales (también denominados bañados o esteros) ocupan Ilanuras bajas inundadas en forma permanente o temporaria con pendientes del orden de $0,02 \%$ y con difíciles condiciones de escurrimiento natural. Entre éstos se distinguen los bañados internos y los bañados costeros a las lagunas. Para el aprovechamiento de las condiciones de los primeros existe una de las mayores obras de infraestructura de riego del pais, la represa de "India Muerta". Con un lago de 3.500 hectáreas constituye la obra de riego por gravedad más importante del país, el uso del agua por toma directa demuestra, por los volúmenes máximos de caudales autorizados, la casi exclusividad del destino arrocero que tiene el recurso, frente al uso industrial y al abastecimiento de agua potable a la población (PROBIDES, 1999). La represa está ubicada a 5 kilómetros de la Ruta 15 ( $\mathrm{km}$ 99), entre las localidades de Velázquez y Lascano. El sistema de riego vinculado a la represa de India Muerta se extiende a lo largo de 180.000 hectáreas y tiene una capacidad de riego para arroz de unas 10.000 hectáreas anuales.

Si bien el impacto en el ecosistema de la desecación parcial de los bañados de Rocha fue muy discutida en su época, su impacto en el crecimiento del cultivo de arroz en la zona es 
indiscutible. En 1978 el Poder Ejecutivo dispuso la actualización de algunos proyectos formulados en la década de los años 1940 por el ingeniero Florencio Martínez Bula para la recuperación productiva de los Bañados de Rocha. Entre dichos proyectos se encontraba la construcción de una represa en el arroyo India Muerta. La finalidad de la represa sería la de regular las crecidas provenientes de una cuenca de 65.700 hectáreas y crear las reservas de agua para riego en la zona de influencia. El agua para riego provendría de canales derivados de la represa, del lago de la represa y de las obras de drenaje complementarias.

Por decreto-ley № 15.142 del 2 de junio de 1981 se declaró "de utilidad pública" la expropiación de los inmuebles necesarios para la ejecución de las obras principales y complementarias del Proyecto Represa en el Arroyo India Muerta, Paraje Paso de las Tropas, departamento de Rocha. Inmediatamente comenzó la construcción de la obra, que finalizó en 1983. La represa consiste en un dique de arcilla y piedra de 3.200 metros de largo y 12 metros de alto. El terraplén contiene 1.763 .000 metros cúbicos de arcilla.

A raíz del represamiento del arroyo, se formó un lago, conocido como Lago de India Muerta, de 3.500 hectáreas y con volumen de agua embalsada de 127.500 .000 metros cúbicos y la profundidad media del lago es de 3,68 metros.

La represa es administrada por la firma Comisaco S.A, integrada por los molinos arroceros Saman S.A. y Coopar. Artigas Barrios, intendente de Rocha, fue gerente de la firma hasta 1985.

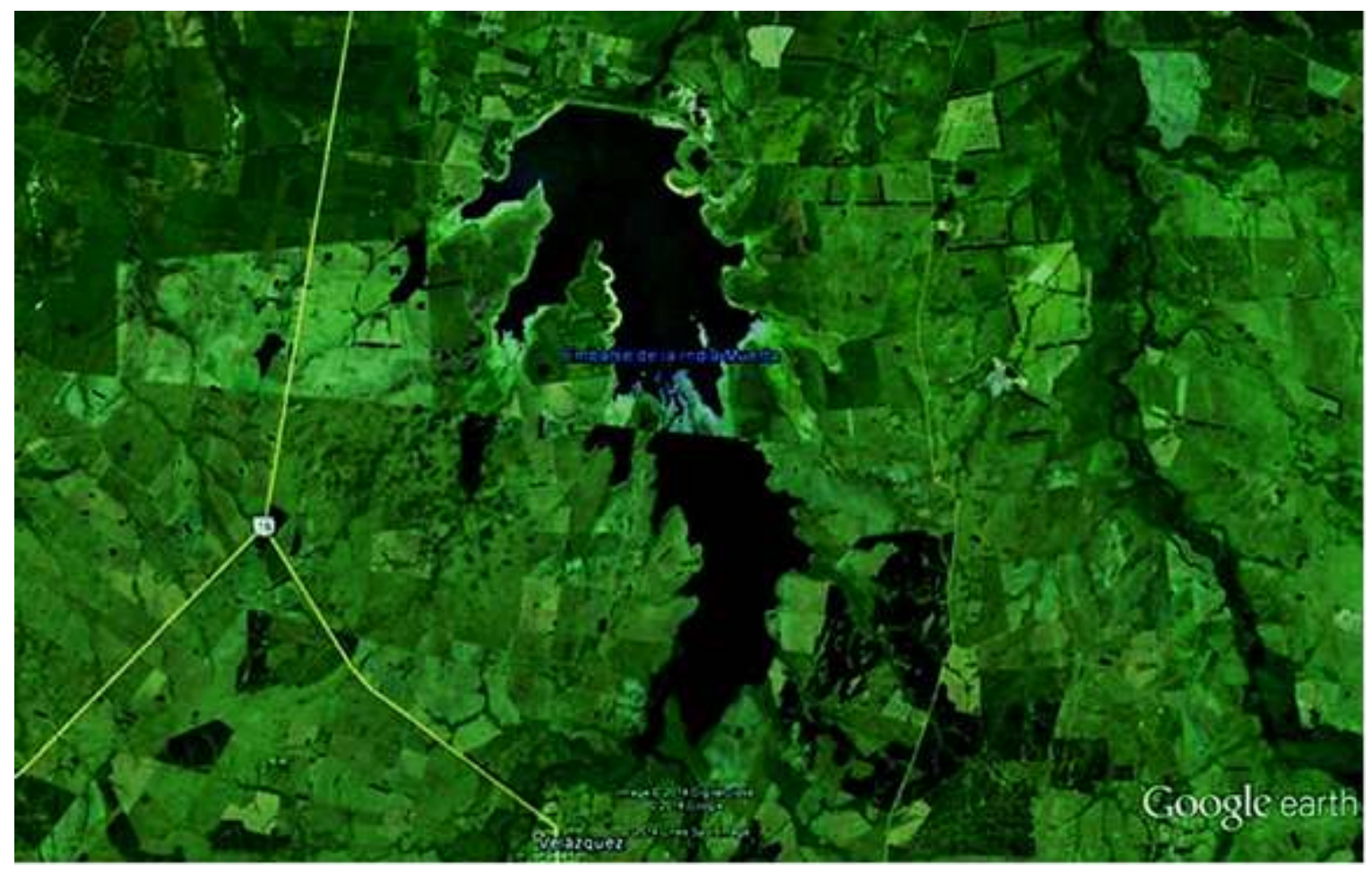

Figura 14. Represa "India Muerta". Fuente: Google Earth, 2017.

En un análisis primario podemos decir que Lascano y Arroz son sinónimos y que durante cuatro generaciones los pobladores han crecido junto con el desarrollo de la explotación del cereal. Esto nos plantea varias temáticas que se producen en torno a la ciudad, sus alrededores, sus actividades, dinámica y pasividad al mismo tiempo.

La asociación de la región con la materia prima permite imaginar el paisaje, sus características, sus sonidos, sus contrastes, sus hitos, caracterizando a la ciudad de una forma que podría decirse, linda con un aspecto de índole patrimonial. 


\section{PROPUESTA}

\section{Educación técnica adaptada}

Lo relevante de la relación arroz-desarrollo en cuanto a la consolidación de la ciudad de Lascano como un polo de referencia en todo el proceso del cereal permite la oportunidad de dar un paso más y colocar a la región como referente introduciendo el concepto de Cultura del Arroz, profesionalizando aún más los procesos, abriendo nuevas oportunidades laborales consolidando a la ciudad y establecer un fuerte núcleo urbano. Se busca con esto seguir con un proceso de descentralización en busca de reducir la macrocefalia de Montevideo, generando un centro de estudios referente a nivel regional lo que provocará una sinergia local y regional obligando a generar planes de desarrollo, mejores y nuevas infraestructuras como también lo que respecta los servicios.

Para ello la introducción de la UTEC (Universidad Tecnológica) será la primera pieza del puzle que se irá armando mediante la retroalimentación de necesidades.

Los Institutos Tecnológicos Regionales (ITR), la expresión de la UTEC en el territorio, se ubicarán en diferentes regiones del interior del país. Actuarán de forma desconcentrada, y cada uno se especializará en determinadas áreas productivas, sin perjuicio de poder brindar otras ofertas educativas de nivel terciario. Los ITR serán los encargados de desarrollar los procesos de enseñanza, investigación y extensión. Administrarán los servicios y las dependencias a su cargo. Propondrán, desarrollarán e implementarán los planes de estudio, carreras y títulos, en coordinación con el Consejo Directivo Central de la UTEC.

Y propondrán convenios y acuerdos estratégicos con entidades públicas y privadas, tanto nacionales como internacionales.

El funcionamiento de la UTEC a través de los ITR busca construir un diálogo con el entorno, mediante una fuerte vocación descentralizadora. Es uno de los ejes fundamentales en el desarrollo de una red que incluya a la mayor cantidad de actores regionales del sector productivo, educativo e institucional. Para determinar la ubicación y la especialización de los ITR, la UTEC se basó en un conjunto de estudios. En primer lugar, se realizó un diagnóstico de las capacidades existentes y faltantes a nivel de todo el territorio nacional en relación a las ofertas y demandas de formación terciaria, teniendo en cuenta los siguientes aspectos:

a. La oferta existente de enseñanza terciaria universitaria y no universitaria en el interior.

b. Los niveles de cobertura educativa alcanzados por la población.

c. Los esfuerzos de traslado requeridos por parte de los estudiantes del interior.

d. El desarrollo productivo de la zona y la potencial demanda laboral de egresados UTEC.

e. La disponibilidad de equipamiento e infraestructura. 


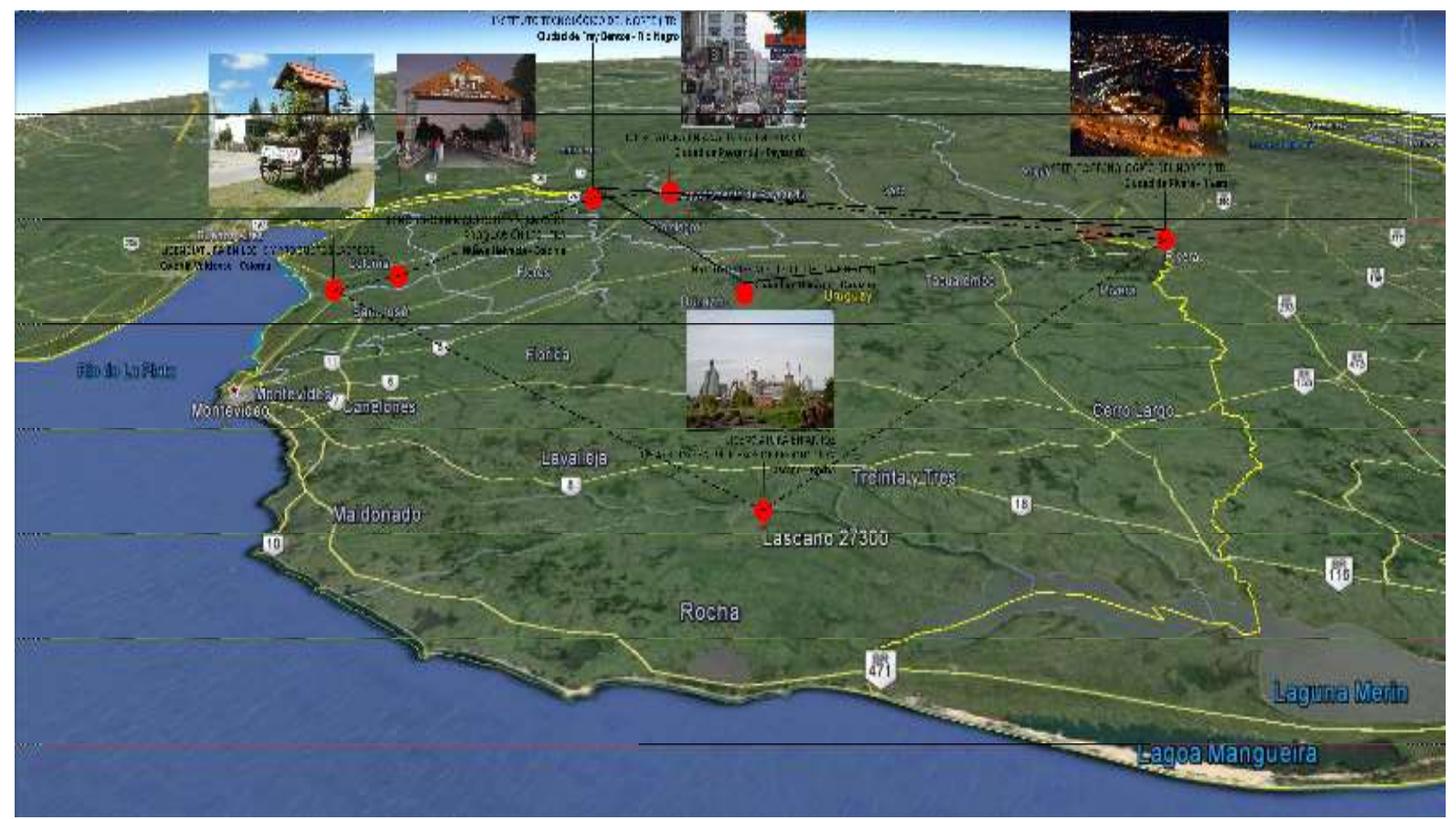

Figura 15. Mapa Educativo. Diego Palau, 2014.

En cuanto al lugar de implantación del centro que albergue la propuesta citada se considera viable un gran predio esquina en las afueras de la ciudad de Lascano sobre la Ruta 14 al cual lo bordea un camino rural, que permitiría una gran flexibilidad dado el tipo de actividad que allí se propone, tanto en el desarrollo de las infraestructuras que se precisan, como la posibilidad de conexiones directas entre los principales nodos de producción regional y sus respectivos centros urbanos.

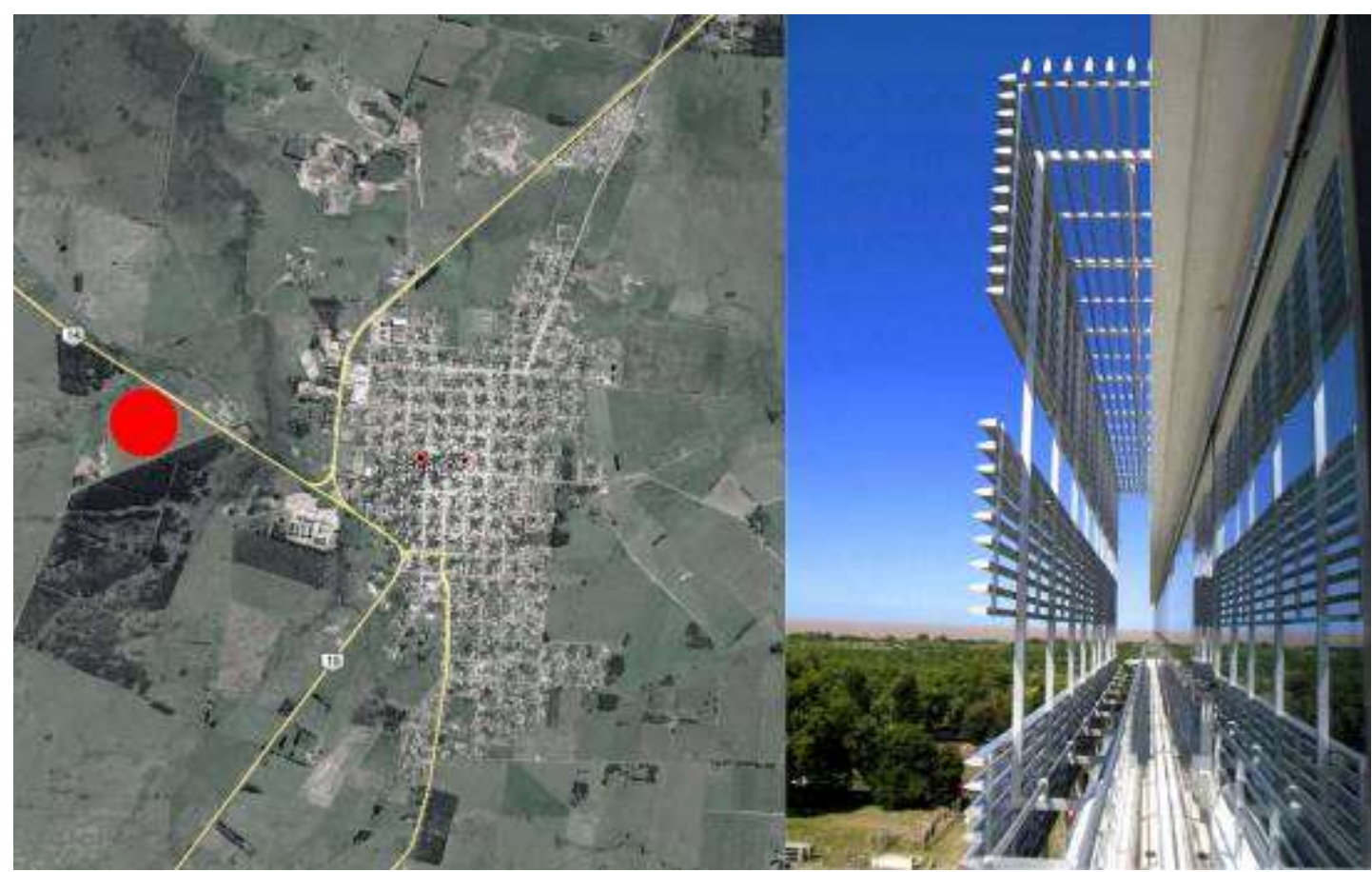

Figuras 16 y 17. Implantación propuesta e imagen ilustrativa. 


\section{BIBLIOGRAFÍA}

Batel, M.B. et al. (2013). Producción Arrocera en el Uruguay. Seminario Uruguay Rural, FAGROUdelaR. Grupo C Ciclo de Producción a la Realidad Agropecuaria.

Baptista, B. et al. (2014). Dinámica del cultivo de arroz en Uruguay en el "nuevo" escenario agropecuario. Relevamiento de Capacidades relativas a la Formación Terciaria en áreas claves para el desarrollo de la Universidad Tecnológica del Uruguay (UTEC) - Informe Región Norte.

DIEA - MGAP (2000). Censo Agropecuario.

DIEA - MGAP (2015). Encuesta de Arroz- Zafra 2013/ 2014.

Intendencia de Rocha. Directrices Departamentales.

Los Departamentos - Rocha (1970). Nuestra Tierra, 10.

Uribe, F. et al. (2013). Producción Arrocera en el Uruguay. Grupo 9 Ciclo de Producción a la Realidad Agropecuaria. 